\title{
Benign prostat hiperplazisinde kombinasyon tedavileri
}

\author{
Combination treatments in benign prostatic hyperplasia
}

Ali Atan®

\section{öz}

BPH medikal tedavisinde tek ilaç tedavisinin başarısız olduğu durumlarda kombinasyon tedavileri kullanılmaktadır. Bu amaçla kullanılan çeşitli kombinasyonlar klinik pratiğimize girmiştir. Her hastanın klinik bulgularına ve beklentilerine uygun olan bir kombinasyon tedavisi seçilebilir. Bu derlemede mecvut kombinasyon tedavilerinin endikasyonları ve faydaları ile ilgili güncel veriler sunulacaktır.

Anahtar Kelimeler: BPH, medical treatment, kombinasyonlar

\section{GíRiș}

Benign prostat hiperplazisi (BPH), prostatın stromal ve epiteliyal komponentlerinde meydana gelen proliferatif sürecin adıdır. BPH 40 yaş üzeri erkeklerin çoğunda histolojik bir bulgu olarak saptanır. BPH'nin klinik tablosunun oluşumunda büyümüş prostat, alt üriner sistem yakınmaları ve mesane çıkım tıkanıklığı önemli rol oynar. Ancak her histolojik BPH varlı̆̆ında mutlaka klinik tablo meydana gelmez. Büyük prostat, alt üriner sistem yakınmaları ve mesane çıkım tıkanıklığı her hastada aynı oranda görülmez. Ayrıca büyük prostat, alt üriner sistem yakınmaları ve mesane çıkım tıkanıklığı arasında bir ilişki olmadığı da belirtilmiştir. ${ }^{[1,2]}$

BPH medikal tedavisinin amaçları BPH ile ilişkili alt üriner sistem yakınmalarını düzeltmek, BPH progresyonunu önlemek, akut üriner retansiyon gelişmesini engellemek, cerrahi ihtiyacını azaltmak ve mümkün olduğu kadar cinsel

Gazi Üniversitesi Tıp Fakültesi, Üroloji Anabilim Dalı, Ankara, Türkiye

Yazışma Adresi/ Correspondence:

Prof. Dr. Ali Atan

Birlik mahallesi, 396 sokak, 14/11, Çankaya 06560 Ankara, Türkiye

Tel: $\quad+905324242082$

E-mail: aliatanpitt@hotmail.com

Gelis/ Received: $\quad 21.10 .2020$

Kabul/ Accepted: 27.10 .2020

\section{ABSTRACT}

Combination therapies are used when single drug therapy fails in BPH medical treatment. Various combinations used for this purpose have entered our clinical practice. A combination therapy appropriate to the clinical findings and expectations of each patient can be selected. In this review, current data on the indications and benefits of these combinations will be presented.

Keywords: BPH, medical treatment, combinations

fonksiyonları korumaktır. BPH ile ilişkili alt üriner sistem yakınmaları Uluslarası Kontinans Derneği'nin Terminoloji raporunda depolama, miksiyon ve postmiksiyon yakınmaları olarak üç gruba ayrılmıştır. ${ }^{[3]} \mathrm{BPH}$ ile ilişkili alt üriner sistem yakınmalarının prostat stromasında bulunan düz kas tonusunun artı̧ıından (dinamik komponent) ve büyümüş olan adenom kitlesinin prostatik uretrada oluşturduğu tıkayıcı etkiden (statik komponent) kaynaklandığ 1 kabul edilmekteydi. ${ }^{[4]}$ Bu nedenle BPH ile ilişkili alt üriner sistem yakınmaları tedavisinde hedef prostat idi ve kısa zaman öncesine kadar BPH medikal tedavisinde sadece alfa bloker ve 5 alfa redüktaz inhibitörü (5-ARi) ilaçlar kullanılmaktaydı. Çünkü alfa bloker ilaçların prostat stromasında bulunan düz kasları gevşeterek, 5-ARi ilaçların ise büyümüş olan adenom kitlesini küçülterek etki yaptığı bilinmektedir.

Ancak daha sonraki çalışmalarda BPH ile ilişkili alt üriner sistem yakınmalarının oluşumunda prostat kadar mesanenin de önemli olduğunun ve erektil disfonksiyon (ED) ile BPH'nin ortak bir fizyopatolojik temele bağlı meydana geldiğinin anlaşılmasından sonra $\mathrm{BPH}$ medikal tedavisinde yeni seçenekler gündeme gelmiştir. ${ }^{[5-7]} \mathrm{BPH}$ medikal tedavisinde alfa bloker ilaçlar, 5-ARi ilaçlar, anti-muskarinikler, fosfodiesteraz tip-5 inhibitörü (PDE-5i) ilaçlar, desmopressin ve fitoterapi kullanılmaktadır. Bu ilaçların tek başlarına kullanımları ile yeterli etkinlik sağlanamadığında kombine tedavileri uygulanmaya başlamıştır. Günümüzde 
sıklıkla kullanılan kombinasyon tedavileri alfa bloker ilaç + 5-ARi ilaç, alfa bloker ilaç + anti-muskarinik ilaç, alfa bloker ilaç + PDE-5i ilaç olmasına karşın çok yeni kombinasyonlarda klinik uygulamalarda görülmektedir. Bu derleme makalede bilinen ve yeni uygulanan kombinasyon tedavilerinin etkinlikleri ile ilgili güncel veriler sunulacaktır.

\section{ALFA BLOKER VE 5-ARI KOMBINASYONU}

Alfa blokerler birkaç saat ile birkaç gün içerisinde etkilerini gösterirler. 5-ARi ilaçlar ancak birkaç ayda etkinliklerini ortaya koyarlar. Endikasyon, prostat spesifik antijen (PSA) düzeyi $1,5 \mathrm{ng} / \mathrm{ml}$ üzeri ve/veya prostat volümü 30-40 ml üzeri olmasıdır. Bu kombinasyondan beklenen fayda semptomatik düzelme ve BPH progresyonunun önlenmesidir. BPH progresyonundan kastedilen akut üriner retansiyon gelişiminin ve cerrahi ihtiyacının azalmasıdır. Yapılan çalışmalarda alfa bloker ve 5-ARi kombinasyonunun en az $\% 50$ oranında akut üriner retansiyon gelişimini önlendiği ve cerrahi ihtiyacını azalttığı saptanmıştır. ${ }^{[8]}$ Alfa bloker + 5-ARi kombinasyonu ile ilgili kanıtlar geniş katılımlı klinik çalışmalardan elde edilmiştir. İlk veriler 6-12 aylık takip süresi olan VA-COOP, ALFIN ve PREDICT çalışmalarından elde edilmiştir. Bu çalışmalarda kombinasyon tedavisinin üstün olmadığı belirtilmektedir. ${ }^{\left[{ }^{[-11]}\right.}$ Ancak dört yildan uzun takip süresi olan MTOPS ve CombAT çalışmalarında ise alfa bloker ve 5-ARi kombinasyonunun monoterapiye göre anlamlı faydalı olduğu gösterilmiştir. [12,13] CONDUCT çalışmasında iki yıl süreyle tek tablet halinde hazırlanmış tamsulosin ve dutasterid kombinasyonu ile izlem-gözlem ve gerektiğinde sadece tamsulosin verilen grup karşılaştırılmıştır. İlaç grubunda progresyon riski olan orta semptom düzeyli hastalarda daha hızlı ve devamlı bir semptomatik düzelme sağlandığı gösterilmiştir. Yazarlar $30 \mathrm{ml}$ üzeri prostat volümü olan orta semptom düzeyli hastalarda tamsulosin ve dutasterid kombinasyonunun izlem gözlem ve sadece tamsulosin tedavisine göre daha faydalı olduğunu belirtmişlerdir. ${ }^{[14]}$ Çok yeni bir çalışmada da alfa bloker ve 5-ARi kombinasyonunun etkinliği incelenmiştir. Bu çalışmada 625 hasta değerlendirilmiştir. Hastaların takip süresi bir yıl ile 12 yıl arasında değişmektedir. On iki yıl tedavide kalan hasta sayısı 17'dir. Araştırıcılar kombinasyon tedavisinin hem kısa hem 12 yıla kadar devam eden uzun dönemde alt üriner sistem yakınmaları ve maksimum idrar akım hızı üzerinde anlamlı düzelme yaptığını bildirmişlerdir. ${ }^{[15]}$ Haque ve ark.'nın Asya'lı erkeklerin dahil olduğu bir çalışmasında orta-ciddi düzeyde BPH ile ilişkili alt üriner sistem yakınmalarının tedavisinde dutasterid ve tamsulosin kombinasyonu tamsulosin ve dutasterid monoterapileri ile karşılaştırılmıştır. Bu çalışmada kombinasyon tedavisi monoterapilere göre daha etkili ve güvenli bir seçenek olarak bulunmuştur. ${ }^{[16]} \mathrm{Bu}$ kombinasyon tedavisi ile etkinlik elde edildikten sonra alfa bloker ilacın 6-9 ay sonra kesilebileceği ve sadece 5-ARi ilaçla devam edilebileceği gösterilmiştir. ${ }^{[17,18]}$ Ancak başlangıç IPSS düzeyi (IPSS >20) yüksek olan hastalarda alfa bloker ilacın 9. ayda bırakılmasının daha uygun olduğu belirtilmektedir. ${ }^{[17]} \mathrm{Bu}$ kombinasyon tedavisi güncel Amerikan Üroloji Derneği ve Avrupa Üroloji Derneği kökenli kılavuzlarda da önerilmektedir. ${ }^{[19,20]}$ Son Avrupa Üroloji Derneği kılavuzunda bu kombinasyon tedavisi için prostat volümünün $40 \mathrm{ml}$ üzerinde olmasının uygun olduğu ve alfa blokerlerin 6. ayda kesilebileceği ifade edilmektedir. ${ }^{[20]}$

Bu kombinasyon tedavisinde kullanılabilen dutasterid ve finasterid'in etkinliğinin karşılaştırıldığı bir çalışma vardır. EPIC (The Enlarged Prostate International Comparator) çalışması prospektif, çok merkezli, randomize, çift kör, 12 aylık finasterid ve dutasteridin karşılaştırıldığı paralel grup çalışmasıdır. Bir yıllık kullanım sonrası prostatın küçülmesi, maksimum idrar akım hızı artışı, BPH ile ilişkili alt üriner sistem yakınmalarının düzelmesi ve yan etkiler açısından iki ilaç benzer bulunmuştur. ${ }^{[21]}$

\section{ALFA BLOKER VE ANTIMUSKARINIK KOMBINASYONU}

Beş ülkenin katıldığı toplum tabanlı bir çalışmada erkeklerin \%51'inde depolama yakınmalarının, \%26'sında ise miksiyon yakınmalarının olduğu saptanmıştır. ${ }^{[22]} \mathrm{Bu}$ nedenle alfa bloker alan kişilerde israr eden depolama yakınmaları olduğunda tedaviye antimuskarinik eklenmesi gereklidir. Çünkü alfa bloker ve 5-ARi ilaçlar depolama yakınmaları üzerinde etkin değildir. ${ }^{[23,24]}$ Bu kombinasyonun kullanımı öncesi ve esnasında hastaların semptom düzeyleri ve semptom tipleri (depolama ve miksiyon), postmiksiyon rezidüel idrar miktarları ve miksiyon durumları iyi sorgulanmalıdır. Oniki haftalık tolterodin ve tamsulosin kombinasyon tedavisinin orta-ciddi alt üriner sistem yakınması olan kişilerde hem semptomlar açısından hem de hayat kalitesi açısından tamsulosine göre anlamlı düzelme sağladığı saptanmıştır. ${ }^{[25]}$ Alfa bloker ve antimuskarinik kombinasyonunun etkinliği ve güvenliği sistemik derleme ve meta-analizlerde de incelenmiş ve faydalı olduğu gösterilmiştir. ${ }^{[2-28]}$ Matsukawa ve ark., alfa bloker monoterapisinin aşırı aktif mesane üzerine sınırlı bir etkiye sahip olduğunu saptamışlardır. Alfa bloker monoterapisi ile ilk üç aylık dönemde fayda elde edilse bile üç ay sonra yakınmaların arttığı gösterilmiştir. Ancak alfa bloker ve antimuskarinik tedavisinin $\mathrm{BPH}$ ile ilişkili depolama yakınmaları üzerinde alfa bloker monoterapisine göre daha etkin olduğu belirtilmektedir. ${ }^{[29]}$ Antimuskarinik ilaçların miksiyon 
basıncı, postmiksiyon rezidüel idrar miktarı ve üriner retansiyon açısından klinik olarak anlamlı değişikliğe yol açmadığı saptanmıştır. ${ }^{[30,31]}$ Buna ek olarak çok merkezli, çok uluslu, çift kör bir çalışmada üç ay süreyle verilen tolterodinin ürodinamik olarak saptanmış mesane çıkım tıkanıklığ olan kişilerde güvenli ve tolere edilebilir bir tedavi olduğu gösterilmiştir. Akut üriner retansiyon gelişimi açısından da plasebo ile farklılığın olmadığ 1 bulunmuştur. ${ }^{[32]}$ Kaplan ve ark., önceden alfa bloker tedavisi almış ancak yeterli faydanın elde edilemediği mesane çıkım tıkanıklığı olan hastalarda altı aylık tolterodin tedavisi sonrası gündüz sık idrara gitme ve gece idrara kalkma sayılarında azalmanın olduğunu saptamışlardır. Bu hastalarda semptom skorunda, maksimum idrar akım hızında ve post miksiyon rezidüel idrar miktarında anlamlı değişimin olduğunu göstermişlerdir. Hiç üriner retansiyon olgusu görülmemiştir. ${ }^{[33]} \mathrm{Bu}$ tedavinin kullanıldığı hastalarda dikkat edilmesi gereken iki önemli parametre vardır. Bunlar maksimum idrar akım hızı ve post miksiyon rezidüel idrar miktarıdır. Tedaviye başlamadan önce maksimum idrar akım hızının $10 \mathrm{ml} / \mathrm{sn}$ altında olmamasına ve postmiksiyon residüel idrar miktarının fazla olmamasına dikkat edilmelidir. Ancak postmiksiyon rezidüel idrar miktarı ile ilgili çalışmalarda farklı sınır değerler belirtilmektedir. Asya çalışmalarında BPH hastalarında antimuskarinik kullanımı için postmiksiyon rezidüel idrar miktarının 50-100 ml arasında olması önerilmektedir. ${ }^{[34]}$ Ancak Amerika ve Avrupa çalışmalarında ise postmiksiyon residüel idrar miktarının 200-250 ml olduğunda bile kullanılabileceği belirtilmektedir. ${ }^{[20,35]}$ Yeni Avrupa Üroloji Kılavuzunda ise postmiksiyon residüel idrar miktarının 150 ml'nin üzerinde olmamaması önerilmektedir. [20] Antimuskarinik monoterapisinin serum PSA değeri 1,3 ng/dl altında olan hastalarda faydasının daha iyi olduğu gösterilmiştir. ${ }^{[36]}$ Ancak son Avrupa Üroloji Derneği kılavuzunda alfa bloker ve antimuskarinik kombinasyonu için serum PSA değerinin önemli olmadığı belirtilmektedir. ${ }^{[20]}$ Mevcut bilgiler ışığında hem Avrupa Üroloji Derneği kılavuzunda hem de Amerikan Üroloji Derneği kılavuzunda depolama yakınmaları ön planda olan kişilerde alfa bloker tedavisinin yeterli olmamasına bağlı daha sonra antimuskarinik eklenebileceği veya başlangıçta alfa blokerler ile beraber kullanımının mümkün olduğu belirtilmektedir. ${ }^{[19,20]}$

Uzun yıllar BPH hastalarında anti-muskarinik kullanımı akut üriner retansiyon gelişeceği endişesiyle yasaklanmıştır. Ancak günümüzde kılavuzların da önerisiyle ciddi endişe duyulmadan antimuskarinikler BPH medikal tedavisinde klinik kullanıma girmiştir. Bunun nedeni anti-muskariniklerin mesane fizyoloji üzerindeki etkilerinin anlaşılmış olmasıdır. Miksiyonun dolma-depolama ve boşaltım fazları vardır. Anti-muskarinikler mesanenin dolma fazında etkilidir ve bu fazda ki kolinerjik aktiviteyi engellerler. Miksiyonun boşaltım fazında detrüsör kasılmasını sağlamak için çok miktarda salınan asetil kolin üzerine etkileri anlamlı değildir. Çünkü boşaltım fazındaki kolinerjik aktivite anti-muskarinik aktivitenin çok üzerindedir. ${ }^{[3]}$

\section{ALFA BLOKER VE PDE-5i ILAC KOMBINASYONU}

Barbosa ve ark.'nın bir çalışmasında BPH ile ilişkili alt üriner sistem yakınması olan erkeklerin \%72,2'sinde ereksiyon bozukluğunun bulunduğu ve alt üriner sistem yakınmalarının ereksiyon bozukluğu için bağımsız bir risk faktörü olduğu saptanmıştır. ${ }^{[38]}$ Alfa blokerlerin yetersiz kaldığı alt üriner sistem yakınması ve erektil disfonksiyonu olan veya olmayan hastalar bu kombinasyon için uygun adaydırlar. Klinik çalışmalarda çeşitli PDE-5i ilaçlar alfa blokerler ile kombine verilmiştir. Beş randomize, plasebo kontrollü çalışmanın meta-analizinde (2 tadalafil $20 \mathrm{mg}$, 1 vardenafil $20 \mathrm{mg}, 2$ sildenafil $25 \mathrm{mg}$ ) kombinasyon tedavisinin alfa blokere göre uluslararası prostat semptom skorunda (IPSS) 1,8'lik azalma, uluslararası erektil fonksiyon indeksi (IIEF) skorunda 3,6'lık artış, maksimum idrar akım hızında (Qmax) 1,5 ml/sn'lik artış yaptığı gösterilmiştir. ${ }^{[39]}$ Daha yeni meta-analiz ve sistemik değerlendirme makalelerinde de alfa bloker ve PDE-5i ilaç kombinasyonunun çok etkin olduğu saptanmıştır. ${ }^{[40-42]} \mathrm{Bu}$ sene yayımlanan 25 randomize kontrollü çalışmanın dahil olduğu bir meta-analizde PDE-5i grubu, alfa bloker grubu ve kombinasyon grubu IPSS, Qmax ve IIEF açılarından karşılaştırılmıştır. Kombinasyon grubunda IPSS düzeyinde anlamlı düzelme bulunur iken Qmax artışı olmasına karşın istatistiksel anlamlılık düzeyinde değildi. Ereksiyon fonksiyonu açısından kombinasyon ve PDE-5i monoterapi grubu arasında fark saptanmamıştır. ${ }^{[43]}$ Ancak her BPH hastası PDE-5i kullanımı için uygun değildir. PDE-5i kullanımının uygun olmadığı durumlar nitrat kullanımı, potasyum kanal açıcı Nikorandil kullanımı, bazı alfa blokerler (terazosin, doksazosin), stabil olmayan anjina pektoris, yeni miyokard enfarktüsü öyküsü ( $<3$ ay), inme ( $<6$ ay), miyokard yetmezliği (New York Kalp Derneği evre >2), hipotansiyon, kötü kontrollü hipertansiyon, ciddi karaciğer ve böbrek yetmezliği, anterior iskemik optik nöropati ve PDE-5i alerjisidir. ${ }^{[20]}$

\section{PDE-5i VE 5-ARI KOMBINASYONU}

Büyük prostat ve 5-ARi tedavisine yetersiz cevabı olan, 5-ARi tedavisine yeterli cevaba karşın erektil disfonksiyon gelişen, 5-ARi ve alfa bloker tedavisine yetersiz cevap veren, tadalafil ve alfa bloker tedavisinin faydalı olmadığı, orta-ciddi alt üriner sistem yakınması ve büyük prostatı 
olan tedavi almamış hem cerrahi işlem hem de medikal tedavilerin cinsel fonksiyonlar üzerindeki olumsuz etkilerini (retrograd ejakulasyon) istemeyen erkeklerin bu kombinasyon tedavisi için uygun adaylar olduğu belirtilmektedir. ${ }^{[44]} \mathrm{Bu}$ kombinasyon ile ilgili uluslararası literatürde kısıtlı sayıda çalışma mevcuttur. İlk çalışma Casabe ve ark.'nın randomize, çift kör çalışmasıdır. Bu çalışmada alt üriner sistem yakınmaları açısından tadalafil ve finasterid kullanan 345 hasta ile finasterid ve placebo kullanan 350 hasta 4., 12. ve 26. haftalarda karşılaştırılmıştır. Çalışmaya dahil etme kriterleri uluslararası prostat semptom skorunun 13 'ten fazla ve prostat volümünün 30 ml'den büyük olmasıdır. Çalışmanın Plasebo/Finasterid grubunda uluslararas1 prostat semptom skorunda 4,5 puan azalma olmuştur, ancak uluslararası erektil fonksiyon indeksi skoru değişmemiştir. Tadalafil/Finasterid grubunda ise uluslararası prostat semptom skoru 5,5 azalmış, uluslararası erektil fonksiyon indeksi skorunda 12 puanlık bir artış gözlenmiştir. Uluslararası prostat semptom skorunda erken ve daha belirgin bir düzelmenin olduğu, hayat kalitesi skorunda da düzelmenin daha iyi olduğu saptandı. Yazarlar bir öneri vermeden önce bu verilerin daha geniş katılımlı ve daha uzun takipli çalışmalar ile desteklenmesi gerektiğini belirtmektedirler. ${ }^{[45]}$ Daha yeni randomize, çift kör bir çalışmada da altı aylık tadalafil ve finasterid tedavisinin finasterid ve plaseboya göre hasta tatmini ve semptomatik düzelme açısından daha etkin olduğu gösterilmiştir. ${ }^{[46]}$

BPH hastalarında 5-ARi ilaçların prostatın küçülmesi, $\mathrm{BPH}$ progresyonunun ve cerrahi ihtiyacının azalması açısından faydalı olması için 6-12 aylık bir kullanım süresinin gerekli olduğu bilinmektedir. Bu hastalarda 5-ARi ilaca PDE-5i eklenmesi ile semptomatik düzelme daha çabuk başlar. Çünkü PDE-5i ilaçların etkisi kullanım sonrası ilk hafta içerisinde görülmeye başlamaktadır. Bu kombinasyon tedavisinin cinsel fonksiyonları bozmadan erken dönemde PDE5-i ilaç ile, uzun dönemde buna 5-ARi ilacın etkisinin eklenmesi ile önemli semptomatik düzelme sağladığı belirtilmektedir. ${ }^{[45,47]}$ Watanabe ve ark., alfa bloker ve dutasterid alan BPH hastalara alfa bloker kesilerek tadalafil ve dutasterid kombinasyonu başlanmasının cinsel fonksiyonlar açısından etkisi değerlendirilmiştir. Bu çalışmanın sonuçlarına göre IPSS ve hayat kalitesi skorunda ve ereksiyon fonksiyonunda düzelme olmasına karşın aşırı aktif mesane yakınmaları değişmemiştir. ${ }^{[4]}$

\section{ALFA BLOKER VE MIRABEGRON KOMBINASYONU}

Beta 3 adrenoreseptör agonisti olan mirabegron aşırı aktif mesane tedavisinde antimuskarinik ilaçlara alternatif olan hem erkek hem de kadınlarda etkinliği ispatlanmış bir ilaç seçeneğidir. ${ }^{[49-51]}$ Japonya kökenli randomize kontrollü iki çalışmada mirabegronun tamsulosine eklenmesi ile depolama yakınmaları ön planda olan BPH hastalarında çok etkili ve iyi tolere edilebilir bir tedavi olduğu saptanmıştır. ${ }^{[0,52]}$ İlk çalışmada hastalar IPSS ile semptomatik açıdan değerlendirilmişlerdir. İkinci çalışmada ise IPSS ile beraber ürodinamik incelemeler yapılmıştır. Ürodinamik çalışmalarda sistometrik kapasitenin arttı̆̆ı, detrüsör aşırı aktivitesinin azaldığı, maksimum idrar akımındaki detrüsör basıncında ve mesane kontraktilite indeksinde bozulma olmadığı saptanmıştır. Ancak bu çalışmalar plasebo kontrollü ve çift kör çalışmalar değildir. Çift kör, plasebo kontrollü yeni bir çalışmada ısrarlı depolama yakınmaları olan hastalarda mirabegronun tamsulosine eklenmesinin etkisi incelenmiştir. İlk dört haftalık sürede hastalara plasebo ve tamsulosin grubuna ayrılmıştır. Daha sonra 12 hafta plasebo + tamsulosin grubu ve mirabegron + tamsulosin grubu oluşturulmuştur. Mirabegronun tamsulosine eklendiği grupta hem depolama yakınmalarında hem de hayat kalitesi skorunda anlamlı bir düzelme sağlanmıştır. Ayrıca mirabegron hastalar tarafından iyi tolere edilmiş, üriner retansiyon ve kardiyovasküler komplikasyonlar açısından plasebodan farklı sonuçlar elde edilmemiştir. ${ }^{[53]}$ Bu çalışma ile ilgili eleştiri noktası çalışmada antimuskarinik grubunun olmamasıdır.

\section{TADALAFIL VE MIRABEGRON KOMBINASYONU}

$\mathrm{Bu}$ kombinasyon tedavisi çok günceldir. Uluslararası literatürde basılmış sadece bir tane prospektif, çok merkezli, paralel gruplu, açık uçlu bir klinik çalışma vardır. Hastalar tadalafil monoterapisi ve tadalafil ile mirabegron kombinasyonu verilmek üzere iki gruba ayrılmıştır. Oniki haftalık tedavi sonrası kombinasyon grubunda BPH ile ilişkili depolama yakınmalarının daha fazla düzeldiği saptanmamıştır. Yazarlar bu kombinasyon tedavisinin hastalarda kullanımının güvenli olduğunu belirtmektedirler. ${ }^{[54]}$

\section{ANTIMUSKARINIK/MIRABEGRON ve 5-ARI KOMBINASYONU}

BPH ile ilişkili AÜSY olan hastalarda dutasterid monoterapisi sonrası israr eden depolama yakınmalarının giderilmesinde antimuskarinik veya mirabegron eklenmesi mantıklı bir seçenek olarak görülmektedir. Ancak bu kombinasyon ile ilgili uluslararası literatürde az sayıda basılmış çalışma vardır. İlk çalışmada sadece dutasterid tedavisi ile düzelmemiş, depolama yakınmaları ön planda alt üriner sistem yakınması bulunan ve prostat volümü $30 \mathrm{ml}$ üzerinde olan erkeklerde dutasterid ve tolterodin kombinasyonunun etkin, güvenilir ve iyi tolere edilen bir seçenek 
olduğu bildirilmektedir. ${ }^{[55]} \mathrm{Bu}$ konu ile ilgili ikinci çalışmada dutasterid monoterapisi sonrası depolama yakınmaları düzelmemiş ve ortalama prostat volümü $39 \mathrm{ml}$ olan $\mathrm{BPH}$ hastalarında dutasteride antimuskarinik veya mirabegron eklenmesi sonrası aşırı aktif mesane yakınmalarının düzeldiği gösterilmiştir. ${ }^{[56]}$ Kosilov ve ark., BPH ile ilişkili AÜSY olan erkeklerde dutasterid ile dutasterid ve antimuskarinik kombinasyonunun etkisini hem AÜSY hem de cinsel fonksiyonlar açısından karşılaştırmışlardır. Kombinasyon tedavisinin AÜSY'larını düzelttiği, erektil fonksiyonu etkilemediği ancak ejakulasyon fonksiyonunu azalttığı saptanmasına karşın genel cinsel tatmin düzeyinde artma sağladığı bulunmuştur. ${ }^{[57]}$

\section{ALFA BLOKER + 5-ARi + ANTIMUSKARINIK}

$\mathrm{Bu}$ kombinasyon teorik olarak çok uygun gözükmesine karşın henüz klinik pratiğimizde çok yer bulmamış bir seçenektir. Uluslararası literatürde bu kombinasyonun uygulandığı çok merkezli, randomize kontrollü iki çalışma vardır. İlk çalışma 24 haftalık, ikinci çalışmada 52 haftalık kullanım sonuçlarını vermektedir. Aynı araştırıcı grubu tarafından yapılmış bu çalışmalarda bu üçlü kombinasyon tedavisinin prostat volümü $30 \mathrm{ml}$ üzerinde ve depolama yakınmalarının ön planda olduğu BPH hastalarında alfa bloker ve dutasterid kombinasyonuna göre daha faydalı olduğu belirtilmektedir. ${ }^{[58,59]} \mathrm{Bu}$ verilerin farklı araştırıcılar tarafindan da desteklenmesi gerekmektedir.

\section{ALFA BLOKER VE SERENOA REPENS KOMBINASYONU}

Alfa bloker ve Serenoa repens kombinasyonu rutin klinik pratiğimizde uygulanan bir kombinasyon değildir. Bu konuda yapılmış sınırlı sayıdaki çalışmada karışık sonuçlar vardır. İlk olarak 2007 yılında yayımlanmış bir çalışmada kombinasyon tedavisinin alfa bloker ve serenoa repens monoterapilerine göre IPSS ve Qmax üzerinde bir üstünlüğünün olmadığ gösterilmiştir. $^{[60]}$ Argirovic'in yaptığı bir çalışmada da benzer sonuçlar elde edilmiştir ve bu kombinasyon tedavisinin IPSS, Qmax ve PMR üzerinde klinik anlamlı bir faydasının olmadığı gösterilmiştir. ${ }^{\left[{ }^{[1]}\right]}$ Daha yeni prospektif, randomize bir çalışmada alfa bloker ve serenoa repens monoterapileri ile kombinasyon tedavisinin 12 aylık kullanım sonrası etkinlikleri karşılaştıııldı. Bu çalışmada kombinasyon tedavisinin monoterapilere göre depolama yakınmalarını azaltmada daha faydalı olduğu bulunmuştur. ${ }^{[62]}$ Boeri ve ark.'nın çalışmasında da BPH nedeniyle AÜSY olan hastalarda 12 aylı Silodosin ve Silodosin + Serenoa repens kombinasyonu tedavisinin etkinliği karşılaştırılmıştır. Bu çalışmada kombinasyon tedavisinin IPSS üzerinde daha faydalı olduğu saptanmıştır. ${ }^{[63]}$
Wang ve ark.'nın güncel bir derleme ve meta-analiz makalesinde BPH medikal tedavisinde kullanılan ilaçların tek başlarına ve kombine kullanımları sonrası etkinlikleri araştırılmıştır. Yazarlar 29384 hastanın dahil edildiği 66 randomize, plasebo kontrollü çalışmayı incelemişleridir. Bu çalışma da uluslararası prostat semptom skoru açısından en başarılı kombinasyonun alfa bloker ve PDE-5i olduğu, maksimum idrar akımı açından en başarılı kombinasyonun ise alfa bloker ve 5-ARi belirtilmektedir. ${ }^{[64]}$

Sonuç olarak BPH ile ilişkili alt üriner sistem yakınmalarının medikal tedavisinde her hastaya uygun tek bir seçenek söz konusu değildir. Bu nedenle hastanın yakınmalarına ve tedavi ile ilgili beklentilerine uygun bir medikal seçeneği sunulmalıdır. Buraya kadar sıraladığımız kombinasyonlar az veya çok uluslararası literatürde yer bulmuş çalışma verilerine dayanmaktadır. Ancak henüz klinik kullanımda olmayan ancak teorik olarak kullanımı mümkün alfa bloker + 5-ARi + PDE-5i, alfa bloker + antimuskarinik + PDE-5i ve 5-ARi + antimuskarinik + PDE-5i gibi diğer kombinasyonlarında yakın gelecekte denenebileceğini ve bu kombinasyonlar ile ilgili verilerin de literatüre gireceğini ümit ediyoruz.

\section{Hakem Değerlendirmesi \\ Dış bağımsız \\ Çıkar Çatışması \\ Yazar çıkar ilişkisi olmadığını beyan etmiştir. \\ Finansal Destek \\ Herhangi bir mali destek alınmamıştır.}

\section{Peer-review}

Externally peer-reviewed.

Conflict of Interest

No conflict of interest was declared by the author.

Financial Disclosure

No financial disclosure was received.

\section{KAYNAKLAR}

1. Shapiro E, Lepor H. Pathophysiology of clinical benign prostatic hyperplasia. Urol Clin North Am 1995;22:285-90. https://pubmed. ncbi.nlm.nih.gov/7539174/

2. Hald T. Urodynamics in benign prostatic hyperplasia: a survey. Prostate Suppl 1989;2:69-77. [CrossRef]

3. D’Ancona C, Haylen B, Oelke M, Abranches-Monteiro L, Arnold E, Goldman H, et al. The International Continence Society (ICS) report on the terminology for adult male lower urinary tract and pelvic floor symptoms and dysfunction. Neurourol Urodyn 2019;38:433-77. [CrossRef]

4. Lepor $\mathrm{H}$. Nonoperative management of benign prostatic hyperplasia. J Urol 1989;141:1283-89. [CrossRef]

5. Roosen A, Chapple CR, Dmochowski RR, Fowler CJ, Gratzke C, Roehrborn CG, et al. A refocus on the bladder as the originator of storage lower urinary tract symptoms: a systematic review of the latest literature. Eur Urol 2009;56:810-20. [CrossRef] 
6. Fullhase C, Chapple C, Cornu JN, Nunzio CD, Gratzke C, Kaplan $\mathrm{SA}$, et al. Systematic review of combination drug therapy for nonneurogenic male lower urinary tract symptoms. Eur Urol 2013;64:22843. [CrossRef]

7. Govorov A, Kasyan G, Priymak D, Pushkar D, Sorsaburu S. Tadalafil in the management of lower urinary tract symptoms: a review of the literature and current practices in Russia. Cent European J Urol 2014;67:167-77. [CrossRef]

8. Fullhasse C, Schneider MP 5-Alpha-Reductase inhibitors and combination therapy. Urol Clin North Am 2016;43:325-36. [CrossRef]

9. Lepor H, Williford WO, Barry MJ, Brawer MK, Dixon CM, Gormley $\mathrm{G}$, et al. The efficacy of terazosin, finasteride, or both in benign prostatic hyperplasia. Veterans Affairs Cooperative Studies Benign Prostatic Hyperplasia Study Group. N Engl J Med 1996;335:533-9. [CrossRef]

10. Debruyne FM, Jardin A, Colloi D, Resel L, Witjes WP, DelaucheCavallier MC, et al. Sustained release alfuzosin, finasteride and the combination of both in the treatment of benign prostatic hyperplasia. European ALFIN Study Group. Eur Urol 1998;34:169-75. [CrossRef]

11. Kirby RS, Roehrborn C, Boyle P, Bartsch G, Jardin A, Cary MM, et al. Efficacy and tolerability of doxazosin and finasteride, alone or in combination, in treatment of symptomatic benign prostatic hyperplasia: the Prospective European Doxazosin and Combination Therapy (PREDICT) trial. Urology 2003;61:119-26. [CrossRef]

12. McConnell JD, Roehrborn CG, Bautista OM, Andriole GL, Dixon CM, Kusek JW, et al. The long-term effect of doxazosin, finasteride, and combination therapy on the clinical progression of benign prostatic hyperplasia. N Engl J Med 2003;349:2387-98. [CrossRef]

13. Roehrborn CG, Siami P, Barkin J, Damião R, Major-Walker K, Nandy I, et al. The effects of combination therapy with dutasteride and tamsulosin on clinical outcomes in men with symptomatic benign prostatic hyperplasia:4-year results from the CombAT study. Eur Urol 2010;57:123-31. [CrossRef]

14. Roehrborn CG, Oyarzabal PI, Calomfirescu N, Brotherton B, Wang F, Palacios JM, et al. Efficacy and safety of a fixed-dose combination of dutasteride and tamsulosin treatment (Duodart) compared with watchful waiting with initiation of tamsulosin therapy if symptoms do not improve, both provided with lifestyle advice, in the management of treatment-naive men with moderately symptomatic benign prostatic hyperplasia:2-year CONDUCT study results. BJU Int 2015;116:45059. [CrossRef]

15. Ong HL, Liao CH, Kuo HC. Long-term combination therapy with $\bigotimes$-blockers and $5 \bigotimes$-reductase inhibitors in benign prostatic hyperplasia: patient adherence and causes of withdrawal from medication. Int Neurourol J 2016;20:356-62. [CrossRef]

16. Haque N, Masumori N, Sakamoto S, Ye Z, Yoon SJ, Kuo HC, et al. Superiority of dutasteride $05 \mathrm{mg}$ and tamsulosin $02 \mathrm{mg}$ for the treatment of moderate-to-severe benign prostatic hyperplasia in Asian men. Int J Urol 2018;25:944-51. [CrossRef]

17. Barkin J, Guimarães M, Jacobi G, Pushkar D, Taylor S, van Vierssen Trip OB; SMART-1 Investigator Group. Alpha-blocker therapy can be withdrawn in the majority of men following initial combination therapy with the dual 5alpha-reductase inhibitor dutasteride. Eur Urol, 2003 44:461-6. [CrossRef]

18. Nickel JC, Barkin J, Koch C, Dupont C, Elhilali M. Finasteride monotherapy maintains stable lower urinary tract symptoms in men with benign prostatic hyperplasia following cessation of alpha blockers. Can Urol Assoc J 2008;2:16-21. [CrossRef]

19. McVary KT, Roehrborn CG, Avins AL, Barry MJ, Bruskewitz RC, Donnell RF, et al. American Urological Association Guideline: Management of Benign Prostatic Hyperplasia (BPH). The American Urological Association. https://www.auanet.org/guidelines/benignprostatic-hyperplasia-(bph)-guideline/benign-prostatic-hyperplasia(2010-reviewed-and-validity-confirmed-2014)
20. Gravas S, Bach T, Bachmann A, Gratzke, Herrmann TRW, Mamoulakis C, et al. Guidelines on the Management of Non-Neurogenic Male Lower Urinary Tract Symptoms (LUTS), incl. Benign Prostatic Obstruction (BPO). European Association of Urolog, 2020. https:// uroweb.org/guideline/treatment-of-non-neurogenic-male-luts/\#5

21. Nickel J, Gilling P, Tammela T, Morrill B, Wilson T, Rittmaster R. Comparison of dutasteride and finasteride for treating benign prostatic hyperplasia: the Enlarged Prostate International Comparator Study (EPICS). BJU Int 2011;108:388-94. [CrossRef]

22. Irwin DE, Milsom I, Hunskaar S, Reilly K, Kopp Z, Herschorn S, et al. Population-based survey of urinary incontinence, overactive bladder, and other lower urinary tract symptoms in five countries: results of the EPIC study. Eur Urol 2006;50:1306-14. [CrossRef]

23. Dmochowski R. Antimuscarinic therapy in men with lower urinary tract symptoms: what is the evidence? Curr Urol Rep 2006;7:462-67. [CrossRef]

24. Yang Y, Zhao XF, Li HZ, Wang W, Zhang Y, Wiao H, Zhang X. Efficacy and safety of combined therapy with terazosin and tolteradine for patients with lower urinary tract symptoms associated with benign prostatic hyperplasia: a prospective study. Chin Med J (Engl) 2007;120:370-4. [CrossRef]

25. Kaplan SA, Roehrborn CG, Rovner ES, Carlsson M, Bavendam T, Guan $\mathrm{Z}$. Tolterodine and tamsulosin for treatment of men with lower urinary tract symptoms and overactive bladder: A randomized controlled trial. JAMA 2006;296:2319-28. [CrossRef]

26. Filson CP, Hollingsworth JM, Clemens JQ, Wei JT. The efficacy and safety of combined therapy with alpha-blockers and anticholinergics for men with benign prostatic hyperplasia: a meta-analysis. J Urol 2013;190:2153-60. [CrossRef]

27. Hao N, Tian Y, Liu W, Wang J, Liu L, Wang K, Hong Li. Antimuscarinics and alpha-blockers or alphablockers monotherapy on lower urinary tract symptoms: a meta-analysis. Urology 2014;83:556-62. [CrossRef]

28. Kim HJ, Sun HY, Choi H, Park JY, Bae JH, Doo SW, et al. Efficacy and safety of initial combination treatment of an alpha blocker with an anticholinergic medication in benign prostatic hyperplasia patients with lower urinary tract symptoms: Updated Meta-Analysis. PLoS One 2017;12: e0169248. [CrossRef]

29. Matsukawa Y, Takai S, Funahashi Y, Kato M, Yamamoto T, Gotoh M. Long-term efficacy of a combination therapy with an anticholinergic agent and an alpha1-blocker for patients with benign prostatic enlargement complaining both voiding and overactive bladder symptoms: A randomized, prospective, comparative trial using a urodynamic study. Neurourol Urodyn 2017;36:748-54. [CrossRef]

30. Herbison P, Hay-Smith J, Ellis G, Moore K. Effectiveness of anticholinergic drugs compared with placebo in the treatment of overactive bladder: Systematic review. BMJ 2003;326:841-4. [CrossRef]

31. Chapple CR. Alpha adrenoceptor antagonists in the year 2000: Is there anything new? Curr Opin Urol 2001;11:9-16. [CrossRef]

32. Abrams P, Kaplan S, De Koning Gans HJ, Millard R. Safety and tolerability of tolterodine for the treatment of overactive bladder in men with bladder outlet obstruction. J Urol 2006;175:999-1004. [CrossRef]

33. Kaplan SA, Walmsley K, Te AE. Tolterodine extended release attenuates lower urinary tract symptoms in men with benign prostatic hyperplasia. J Urol 2005;174:2273-5. [CrossRef]

34. Yang Y, Zhao XF, Li HZ, Wang W, Zhang Y, Xiao H, Zhang X. Efficacy and safety of combined therapy with terazosin and tolteradine for patients with lower urinary tract symptoms associated with benign prostatic hyperplasia: a prospective study. Chin Med J (Engl) 2007;120:370-4. [CrossRef]

35. Chapple C, Herschorn S, Abrams P, Sun F, Brodsky M, Guan Z. Tolterodine treatment improves storage symptoms suggestive of overactive bladder in men treated with alpha-blockers. Eur Urol 2009;56:534-41. [CrossRef] 
36. Roehrborn CG, Kaplan SA, Kraus SR, Wang JT, Bavendam T, Guan Z. Effects of serum PSA on efficacy of tolterodine extended release with or without tamsulosin in men with LUTS, including OAB. Urology 2008;72:1061-7. [CrossRef]

37. Andersson KE. Detrusor myocyte activity and afferent signaling. Neurourol Urodyn 2010;29:97-106. [CrossRef]

38. Barbosa JA, Muracca E, Nakano E, Assalin AR, Cordeiro P, Paranhos $\mathrm{M}$ et al. Interactions between lower urinary tract symptoms and cardiovascular risk factors determine distinct patterns of erectile dysfunction: a latent class analysis. J Urol 2013;190:2177-82. [CrossRef]

39. Gacci M, Corona G, Salvi M, Vignozzi L, McVary KT, Kaplan SA, et al. A systematic review and meta-analysis on the use of phosphodiesterase 5 inhibitors alone or in combination with alpha-blockers for lower urinary tract symptoms due to benign prostatic hyperplasia. Eur Urol 2012;61:994-1003. [CrossRef]

40. Wang XH, Wang X, Shi MJ, Li S, Liu T, Zhang XH. Systematic review and meta-analysis on phosphodiesterase 5 inhibitors and $\alpha$-adrenoceptor antagonists used alone or combined for treatment of LUTS due to BPH. Asian J Androl 2015;17:1022-32. [CrossRef]

41. Gacci M, Andersson KE, Chapple C, Maggi M, Mirone V Oelke M, et al. Latest evidence on the use of phosphodiesterase type 5 inhibitors for the treatment of lower urinary tract symptoms secondary to benign prostatic hyperplasia. Eur Urol 2016;70:124-33. [CrossRef]

42. Zhang J, Li X, Yang B, Wu C, Fan Y, Li H. Alpha-blockers with or without phosphodiesterase type 5 inhibitor for treatment of lower urinary tract symptoms secondary to benign prostatic hyperplasia: a systematic review and meta-analysis. World J Urol 2019;37:143-53. [CrossRef]

43. Kallidonis P, Adamou C, Kotsiris D, Ntasiotis P, Verze P, Athanasopoulos A; Young Academic Urologists of the European Association of UrologyEndourology Working Party. Combination therapy with alpha-blocker and phosphodiesterase-5 inhibitor for improving lower urinary tract symptoms and erectile dysfunction in comparison with monotherapy: a systematic review and meta-analysis. Eur Urol Focus 2020;6:537-58. [CrossRef]

44. Elkelany OO, Owen RC, Kim ED. Combination of tadalafil and finasteride for improving the symptoms of benign prostatic hyperplasia: critical appraisal and patient focus. Ther Clin Risk Manag 2015;11:50713. [CrossRef]

45. Casabé A, Roehrborn CG, Da Pozzo LF, Zepeda S, Henderson RJ, Sorsaburu S, et al. Efficacy and safety of the coadministration of tadalafil once daily with finasteride for 6 months in men with lower urinary tract symptoms and prostatic enlargement secondary to benign prostatic hyperplasia. J Urol 2014;191:727-33. [CrossRef]

46. Roehrborn CG, Casabé A, Glina S, Sorsaburu S, Henneges C, Viktrup L. Treatment satisfaction and clinically meaningful symptom improvement in men with lower urinary tract symptoms and prostatic enlargement secondary to benign prostatic hyperplasia: Secondary results from a 6-month, randomized, double-blind study comparing finasteride plus tadalafil with finasteride plus placebo. Int J Urol 2015;22:582-87. [CrossRef]

47. Olesovsky C, Kapoor A. Evidence for the efficacy and safety of tadalafil and finasteride in combination for the treatment of lower urinary tract symptoms and erectile dysfunction in men with benign prostatic hyperplasia. Ther Adv Urol 2016;8:257-71. [CrossRef]

48. Watanabe D, Yamashita A, Miura K, Mizushima A. Effects on sexual function in Japanese patients with benign prostatic hyperplasia upon switching from combination therapy with $\alpha 1$ blocker and dutasteride to combination therapy with tadalafil and dutasteride. Aging Male 2018;20:1-6. [CrossRef]

49. Chapple CR, Cardozo L, Nitti VW, Siddiqui E, Michel MC. Mirabegron in overactive bladder: a review of efficacy, safety, and tolerability. Neurourol Urodyn 2014;33:17-30. [CrossRef]
50. Wada $N$, Iuchi $H$, Hashizume $K$, Matsumoto $S$, Kakizaki $H$. Urodynamic efficacy and safety of mirabegron add-on treatment with tamsulosin for Japanese male patients with overactive bladder. Low Urin Tract Symptoms 2016;8:171-6. [CrossRef]

51. Chapple C, Siddiqui E. Mirabegron for the treatment of overactive bladder: a review of efficacy, safety and tolerability with a focus on male, elderly and antimuscarinic poor-responder populations, and patients with OAB in Asia. Expert Rev Clin Pharmacol 2017;10:131-51. [CrossRef]

52. Ichihara K, Masumori N, Fukuta F, Tsukamoto T, Iwasawa A, Tanaka Y. A randomized controlled study of the efficacy of tamsulosin monotherapy and its combination with mirabegron for overactive bladder induced by benign prostatic obstruction. J Urol 2015;193:9216. [CrossRef]

53. Kakizaki H, Lee KS, Yamamoto O, Jong JJ, Katou D, Sumarsono B, et al. Mirabegron Add-on Therapy to Tamsulosin for the Treatment of Overactive Bladder in Men with Lower Urinary Tract Symptoms: A Randomized, Placebo-controlled Study (MATCH). Eur Urol Focus 2020;6:729-37. [CrossRef]

54. Yamanishi T, Kaga K, Sakata K, Yokoyama T, Kageyama S, Fuse M, Tokunaga S. A randomized controlled study of the efficacy of tadalafil monotherapy versus combination of tadalafil and mirabegron for the treatment of persistent overactive bladder symptoms in men presenting with lower urinary tract symptoms (CONTACT Study). Neurology and Urodynamics 2020;39:804-12. [CrossRef]

55. Chung DE, Te AE, Staskin DR, Kaplan SA. Efficacy and safety of tolterodine extended release and dutasteride in male overactive bladder patients with prostates $>30$ grams. Urology 2010;75:1144-8. [CrossRef]

56. Maeda T, Kikuchi E, Hasegawa M, Ishioka K, Hagiwara M, Miyazaki $Y$, et al. Solifenacin or mirabegron could improve persistent overactive bladder symptoms after dutasteride treatment in patients with benign prostatic hyperplasia. Urology 2015;85:1151-5. [CrossRef]

57. Kosilov K, Kuzina I, Kuznetsov V, Gainullina Y, Kosilova L , Karashchuk E, et al. The risk of sexual dysfunction and effectiveness of treatment of benign prostatic hyperplasia with severe lower urinary tract dysfunction with combination of dutasteride and solifenacin. J Sex Med 2018;15:1579-90. [CrossRef]

58. Yamanishi T, Asakura H, Seki N, Tokunaga S. Efficacy and safety of combination therapy with tamsulosin, dutasteride and imidafenacin for the management of overactive bladder symptoms associated with benign prostatic hyperplasia: a multicenter, randomized, open-label, controlled trial (DIrecT Study). Int J Urol 2017;24:525-31. [CrossRef]

59. Yamanishi T, Asakura H, Seki N, Tokunaga S. A 52-week multicenter randomized controlled study of the efficacy and safety of add-on dutasteride and imidafenacin to tamsulosin in patients with benign prostatic hyperplasia with remaining overactive bladder symptoms (DIrecT study). Low Urin Tract Symptoms 2019;11:115-21. [CrossRef]

60. Hizli F, Uygur MC. A prospective study of the efficacy of serenoa repens, tamsulosin, and serenoa repens plus tamsulosin treatment for patients with benign prostate hyperplasia. Int Urol Nephrol 2007;39:879-86. [CrossRef]

61. Argirović A, Argirović D. Does the addition of Serenoa repens to tamsulosin improve its therapeutical efficacy in benign prostatic hyperplasia? Vojnosanit Pregl 2013;70:1091-96. [CrossRef]

62. Ryu YW, Lim, SW, Kim JH, Ahn SH, Choi JD. Comparison of tamsulosin plus serenoa repens with tamsulosin in thevtreatment of benign prostatic hyperplasia in Korean men:1-year randomized open label study. Urol Int 2015;94:187-93. [CrossRef]

63. Boeri L, Capogrosso P, Ventimiglia E, Pederzoli F, Moretti D, Dehòet F, et al. Clinically Meaningful Improvements in LUTS/BPH Severity in Men Treated with Silodosin Plus Hexanic Extract of Serenoa Repens or Silodosin Alone. Sci Rep 2017;7:15179. [CrossRef]

64. Wang X, Wang X, Li S, Meng Z, Liu T, Zhang X. Comparative effectiveness of oral drug therapies for lower urinary tract symptoms due to benign prostatic hyperplasia: a systematic review and network meta-analysis. PLoS One 2014;9:e107593. [CrossRef] 